\title{
Prevalence of work related musculoskeletal disorders among canteen staff of Kathmandu University
}

\section{Shakya NR', Shrestha $S^{2}$}

'Nishchal Ratna Shakya, Lecturer; Department of Physiotherapy; Kathmandu University School of Medical Sciences, Kathmandu University, Dhulikhel, Nepal; ${ }^{2}$ Shreya Shrestha, Physiotherapist; Department of Physiotherapy; Sahara Physiotherapy Hospital Pvt. Ltd., Maharajgunj, Kathmandu, Nepal.

\begin{abstract}
Background: Work related musculoskeletal disorders are common complaint at workplace and is a leading cause of illness. A kitchen worker's work consists of continuous long standing hours, awkward positions, lifting heavy loads and repetitive activities. The prevalence of musculoskeletal disorders is related to demographic factors, occupational, psychosocial factors and ergonomic risk factors at workplace. Canteen staffs are considered to be at higher risk of having musculoskeletal disorders.

Objectives: To evaluate the prevalence of work related musculoskeletal disorders among the canteen staffs of Kathmandu University and to find association between risk factor and musculoskeletal disorders among the canteen staffs.

Methodology: We carried out a cross-sectional descriptive study interviewing 40 participants for filling the demographic data and the standardized Nordic questionnaires for assessing the prevalence of musculoskeletal disorders among the canteen staffs of Kathmandu University. Data were analyzed using Statistical Package for the Social Sciences version 16. Results: We found that out of 40 participants, $60 \%$ reported having at least one work related musculoskeletal symptoms in the past 12 month. Back pain (35\%) was most commonly reported disorder followed by neck (27.5\%) and ankle pain (27.5\%).

Conclusion: Prevalence of work related musculoskeletal disorder among the canteen staffs of Kathmandu University was found to be high. So it is essential to take necessary steps to minimize musculoskeletal disorder and develop preventive strategies.
\end{abstract}

Key words: Canteen; Musculoskeletal disorder; Nordic questionnaires

DOI: https://doi.org/10.3126/jkmc.v7i4.23318

\section{INTRODUCTION}

W ork-related musculoskeletal disorders (WMSDs) are defined as symptoms caused or aggravated by occupational risk factors, including discomfort, damage or persistent pain in body structures ${ }^{1}$. WMSDs are mostly associated with laborers working in the manufacturing industry but over the years, it has been prevalent in most sectors such as healthcare, hotels, and educational institutions ${ }^{2,3}$. Repetitive manual work, lifting and forceful movement and awkward postures are contributing factors for musculoskeletal disorders ${ }^{3}$. The World Health Organization (WHO), recognizing the impact of 'work-related' musculoskeletal diseases, has

Address for correspondence

Nishchal Ratna Shakya

Lecturer, Department of Physiotherapy

Kathmandu University School of Medical Sciences (KUSMS)

P.O.Box: 11008, Dhulikhel, Kavre, Nepal

E-mail: nishchalrs@gmail.com characterized WMSDs as multifactorial, indicating that a number of risk factors contribute to and exacerbates these maladies ${ }^{4}$. These types of injuries of the soft tissues are referred to by many names, including WMSDs, repetitive strain injuries (RSI), repetitive motion injuries (RMI), and cumulative trauma disorders (CTDs) ${ }^{5}$. WMSD can be defined by impairments of bodily structures such as muscles, joints, tendons, ligaments, nerves, bones and the localized blood circulation system, caused or aggravated primarily by work itself or by the work environment ${ }^{6}$.

A kitchen worker's work is characterized by long standing hours, constant leaning forward of the body, repetitive upper body movements, lifting heavy items in awkward positions, static postures and heavy workloads. These include prolonged grasping of cooking utensils, tossing a wok, and cutting vegetables, all of which require the forceful exertion of hands, wrists, 
and forearms ${ }^{7}$. In addition, a cook often has to keep moving the wrist in repetitive cutting activities ${ }^{8}$. Other factors can also increase the risk of WMSDs, such as work environment and organization, individual characteristics and capacities of the worker, and psychosocial risk factors such as job satisfaction, perceived workload, job autonomy, monotonous work and stress at work and leisure time ${ }^{9-13}$. Smoking cigarette, sleep hours and break hours are also among the risk factors for WMSDs ${ }^{14}$. It has been found that there was a high incidence of symptoms and ailments of the muscular and skeletal systems amongst the canteen kitchen workers ${ }^{15}$. Kitchen workers in catering industry were found to be at high risk of developing WMSDs, with 12 months prevalence rate of $67.5 \%$, and most prevalent at the lower back with $65.8 \%$ among commercial kitchen workers in a study conducted in South India ${ }^{16}$. A study conducted among professional cooks working in school lunch services showed prevalence of $74.3 \%$ low back pain conducted in Japan ${ }^{14}$.

The university canteens are mainly used by students and staffs at breakfast and lunch time. Generally, cooking and washing tasks in university canteens are done manually without modern cooking facilities. When working in a canteen, there is more of manual work resulting in increased use of muscles in a limited space and time constraint and thereby increasing stress ${ }^{17}$. Risk factors associated with Musculoskeletal Disorders may differ in canteen workers in relation to working hours, work division, work setting and schedule. Behaviors or attitudes of employees play a major role in determining the quality of service because the employees come in direct contact with customers when providing services. Decreased productivity and job satisfaction resulting in financial loss along with increased stress level and absenteeism is caused by WMSDs. This has a significant impact on quality of life of workers as well as there may be a decline in quality services provided to the consumers. Also, being a part of the holistic team, the health impact identification in such group is necessary. The canteen staffs are at higher risk of having WMSD and their knowledge in prevention strategies is unknown ${ }^{18-20}$.

There are wide number of studies worldwide to evaluate the musculoskeletal disorders in different work sectors including canteen or kitchen workers. There has been several studies among the hospital staffs including doctors, nurses, cleaning staff and University canteen workers ${ }^{10,17}$ but in Nepal, only few studies have been conducted to analyze the musculoskeletal disorders in various sector workers especially health care workers like in surgeons ${ }^{21}$, dentists ${ }^{22}$, young workers in the brick kilns $^{23}$ but there is no study on prevalence and risk factors associated with WMSDs among kitchen workers in Nepal. The primary objective of this study is to evaluate the prevalence of work related musculoskeletal disorders among canteen staffs of Kathmandu University and also to find the association between risk factors and musculoskeletal disorders.

\section{METHODOLOGY}

We conducted a cross sectional descriptive study to evaluate the prevalence of work related musculoskeletal disorder among the canteen staffs of Kathmandu University. It included three canteens of Kathmandu University School of Medical Sciences (KUSMS) and two canteens of Kathmandu University. All the canteen staffs working at Kathmandu University more than a year were included and those with congenital deformities and recent injuries were excluded. Out of total 41 participants, one was excluded due to recent injury. All subjects were asked to sign a consent form before participating in the project. The data collection for the study was conducted from January to June 2017. Personal data information was obtained through interview. The interview questionnaires included personal information, duration of employment, duration of work in a day and week, working shifts, overtime duty, canteen activities, break hours, standing hours, smoking behavior and sleep hours. The baseline characteristics of the study population were analyzed using Descriptive statistics.

We used the Standardized Nordic musculoskeletal questionnaire (NMQ), developed by Kuorinka in 1987, to assess the musculoskeletal symptoms ${ }^{24}$. Nordic questionnaires (specificity-88\%; sensitivity-92\%) consist of general and specific questionnaires part and only general part was used in the study. The general questionnaires consisted of 40 items identifying the areas of body causing musculoskeletal disorders. Body chart presented helped in better identification of location of discomfort or pain. We translated the NMQ into Nepali Language, and added the visual analogue scale (VAS) to measure the intensity of the symptoms. The NMQ has advantages compared to other survey methods, as respondents find it easier to complete the NMQ's simpler questionnaire, and the NMQ's standardized results make comparison more straightforward when conducting epidemiological studies. We asked the study participants, "Have you suffered an ache, pain or discomfort at your neck, shoulder, elbow, wrist/hand, back, lower back, hip/thigh, knee, or ankle/foot during 
the last 12 months?" In addition, we inquired "Have you at any time during the last 12 months been prevented from doing your normal work (at home or away from home) because of the trouble?", "Have you seen a physician for this condition during the last 12 months?" and "Have you had any physical difficulty during the last seven days?" The respondents were requested to gauge their pain on a 10-point scale from 0 to 9 points. Among the respondents who experienced any symptom in any of the nine body areas in the past 12 months, we determined those who suffering symptoms with a pain score of five or more points to be positive criteria for musculoskeletal symptoms ${ }^{2}$. Prevalence of work related musculoskeletal disorders was analyzed according to the scores on individual tests of Nordic musculoskeletal Questionnaire. Chi square test was used to assess the association between variables and musculoskeletal disorders.

Permission letter and ethical approval was taken from respected department and from Kathmandu University Institutional review committee respectively before conducting the research. Written consent was taken from selected participants prior to data collection. The participants were explained about the purpose, risks and benefits of the study. The Nordic questionnaire was interviewed one on one by the researcher. The data was entered and analyzed in Statistical Package for the Social Sciences (SPSS) version 16.

\section{RESULTS}

Participants included 22 (55\%) male and 18 female (45\%) among which $87.5 \%$ were married. Table 1 represents the demographic characteristics of our study participants. The mean age was $31.33 \pm 8.19$. Most of the canteen staff had secondary education (42.5\%) and higher education (20\%). We found that $10 \%$ of the total participants were smokers.

The prevalence of work related musculoskeletal disorder in the past 12 months was found to be $60 \%$ among the canteen staffs of Kathmandu University. According to 12 months prevalence as represented in Fig. 1, most commonly reported WMSD was low back pain (35\%) followed by neck and ankle(27.5\%). Fig. 2 represents the prevalence of WMSD in the past seven days which was found to be ankle (25\%), knee (20\%) and lower back (18\%).

\section{Table 1: Demographic Characteristics of the participants}

\begin{tabular}{lc|}
\hline Variables & Mean \pm SD \\
\hline Age & $31.32 \pm 8.19$ \\
\hline Weight & $67.23 \pm 12.37$ \\
\hline Height & $1.60 \pm 0.662$ \\
\hline BMI & $25.69 \pm 4.165$ \\
\hline Working days & $6.12 \pm 1.09$ \\
\hline Working hours & $8.8 \pm 2.01$ \\
\hline Working experience(years) & $6.2 \pm 4.77$ \\
\hline Standing hours & $6.6 \pm 2.50$ \\
\hline Sleep hours & $7.85 \pm 1.77$ \\
\hline Lunch time( minutes) & $25.62 \pm 19.35$ \\
\hline
\end{tabular}

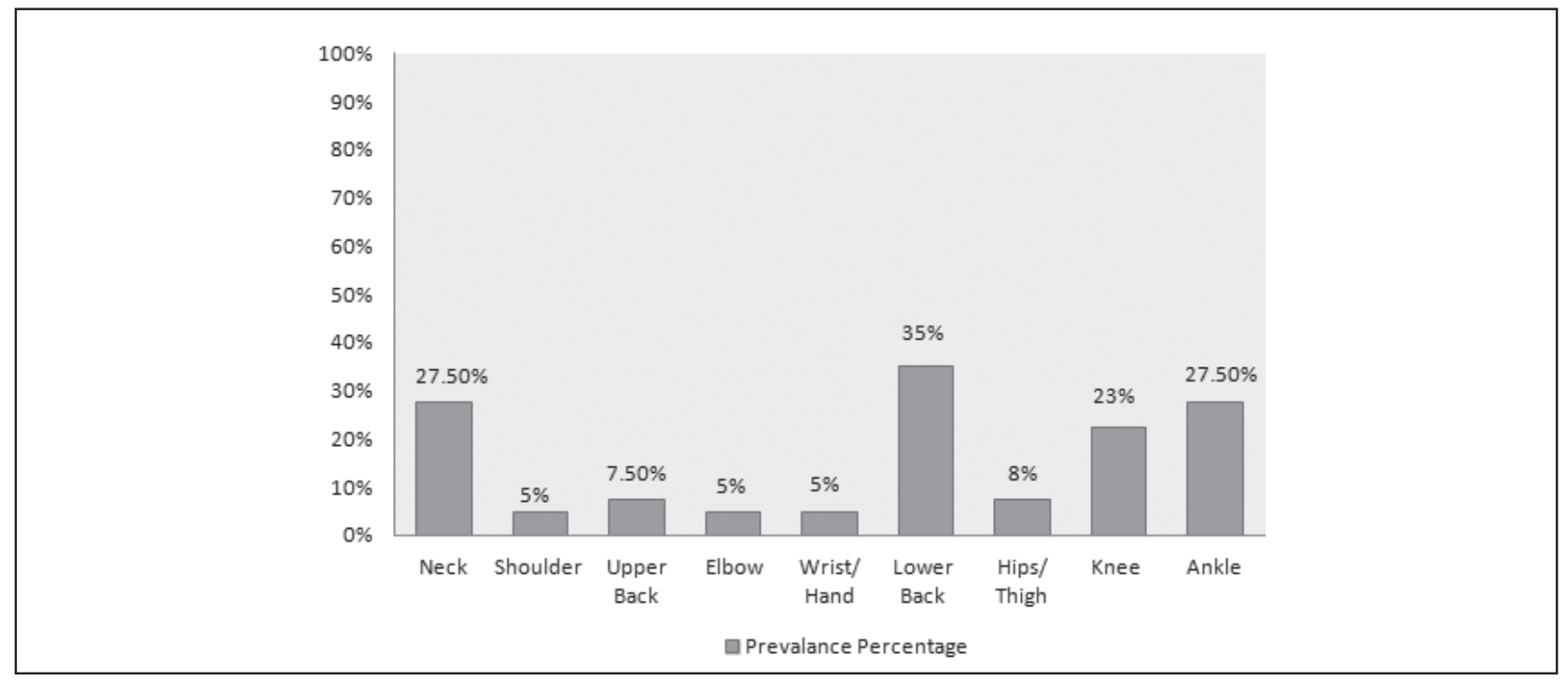

Figure 1: Prevalence of work related musculoskeletal disorders in past twelve months in specific body parts 


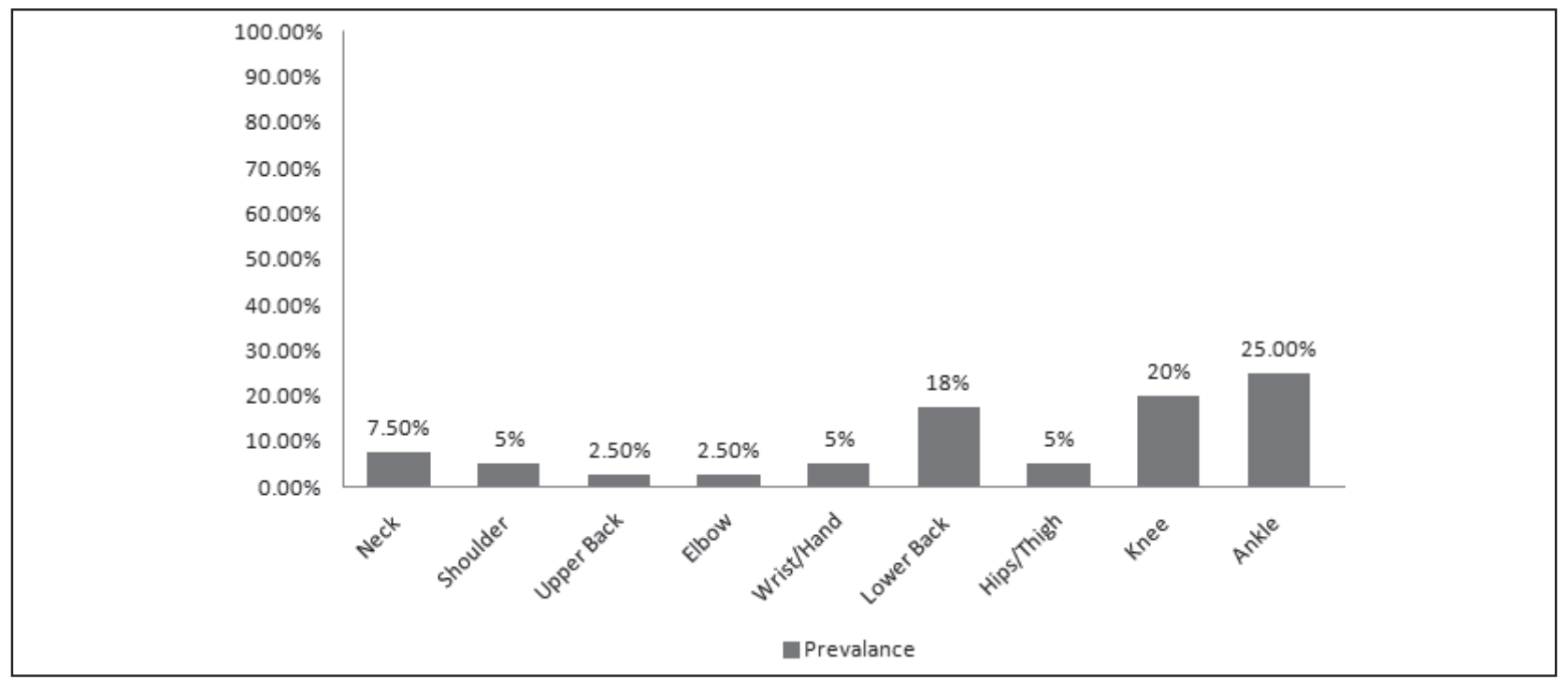

Figure 2: Prevalence of work related musculoskeletal disorders in past seven days

\section{DISCUSSION}

This study examined the prevalence of WMSDs and the association of risk factors with the musculoskeletal disorders. Out of 40 participants, $60 \%$ reported pain or discomfort in at least one of the body region which is very valid when compared to studies previously conducted in other countries among the kitchen workers. In a study conducted by S. Shankar et al 2015 in South India, the results revealed that $67.5 \%$ of the male kitchen workers experienced WMSDs during the past 12 months $^{16}$. Similarly, it is found that among Chinese restaurant cooks, it was $86 \%$, western-style restaurants had $42 \%$ whereas $11.5 \%$ in Japanese restaurant cooks ${ }^{25,26}$. Therefore, it is also accepted that there are wide variations in the range of prevalence estimates across different settings.

In the current study, the WMSDs was found to be most prevalent with low back pain (35\%) followed by neck and ankle/foot pain which accounted for $27.5 \%$ each and then followed by other body parts as Hip, Upper back, shoulder, elbow and wrist. Similar to the results of this study, the systematic review on prevalence of WMSD in catering industry (2010) showed most commonly affected body parts as lower back and neck, but this is then followed by shoulder, elbow, upper leg and ankle/ foot $^{13}$. Interestingly, this systematic review study has found a wide range of WMSD prevalence (3-86\%) in catering employees across different body parts and had concluded that such a wide range might be due to the broad types of canteens and restaurants surveyed. Some were Chinese restaurants or Western restaurants while the rest were school centers, medical centers, catering schools, commissary food service companies and so on. Further, they had concluded that the diversity in organization, work methods, workplace layout, and tool and equipment design could all contribute to these differences including the diversity in job titles of the workers (with different physical demands) and widely varying sample sizes.

The major prevalence of lower back pain in the current study can be the results of long standing hours and lifting activities in awkward postures as in other previous studies. Epidemiological studies have revealed that low back pain is related to awkward postures and prolonged standing ${ }^{27}$, including trunk flexion with or without rotation, combined trunk flexion and manual lifting, frequent trunk bending and prolonged static trunk flexion. It has been shown that prolonged static trunk flexion may subject the spine to reduced activity of multifidus, provoke flexion relaxation phenomenon of the thoracic erector spinae resulting in the creep response of the lumbar spinal tissues, reduce the oxygenation of lumbar extensors due to the constant isometric contraction, and increase the intradiscal pressure ${ }^{28}$. The canteen staffs of Kathmandu University with the musculoskeletal disorders were found to undergo long standing hours, repetitive activities of cooking, cutting, lifting, cleaning, washing dishes and awkward postures. According to Messing and Kilborn (2001), prolong standing hours can result in reduced plantar pain threshold over the day ${ }^{29}$ which would further help aggravate the musculoskeletal disorders. However, there was no proper allocation or distribution of work in the Kathmandu University canteen workers. Although the break hours were not fixed, the canteen 
staffs took lunch break according to their workload which showed mean break time to be 25 minutes. The canteen staffs worked for around eight hours a day with around average more than six hours of standing every day.

In the current study, $10 \%$ of total participants reported smoking among which had musculoskeletal disorders. The evidence of smoking and low back pain association has been mentioned in some studies. Studies have shown that smoking causes decrease in bone mineral density in the lumbar spine. Abate $\mathrm{M}$ et al. 2013 in their review study reported that a large amount of clinical and experimental research showed cigarette smoking has deleterious effects on the musculoskeletal system, and worsens the prognosis of several musculoskeletal disorders ${ }^{30}$.

However, there was no statistically significant difference found in the independent variables such as education, cigarette smoking, Body mass index etc. in the current study. The relationship between reported musculoskeletal disorders and variables like total years of work experience, prolonged standing in work was also statistically insignificant. This current study had only 40 participants due to which significant correlation between musculoskeletal disorder and other demographic variables could not be assessed. The secondary objective to find the association between musculoskeletal disorder and risk factors could not be evaluated due to inadequate sample size but it portrays an overview of musculoskeletal disorders in the University canteen staff.

\section{REFERENCES}

1. Bernal D, Campos-Serna J, Tobias A, Vargas-Prada S, Benavides FG, Serra C. Work-related psychosocial risk factors and musculoskeletal disorders in hospital nurses and nursing aides: a systematic review and meta-analysis. Int J Nurs Stud. 2015 Feb;52(2):63548. [DOI]

2. Lee JW, Lee JJ, Mun HJ, Lee K-J, Kim JJ. The Relationship between Musculoskeletal Symptoms and Work-related Risk Factors in Hotel Workers. Ann Occup Environ Med. 2013 Oct 11;25:20. [PubMed]

3. Ibrahim NI, Mohanadas D. Prevalence of musculoskeletal disorders among staffs in specialized healthcare centre. Work. 2012;41(1):2452-60. [Full Text]

4. World Health Organization. Expert Committee on Identification and Control of Work-Related Diseases
Therefore, the main limitation of the study was the small study population at the university canteen. Due to less sample size, the result of this study may not represent work related musculoskeletal disorders of all University canteen workers in Nepal. Another limitation was that the questions were asked relying on respondents' recollection of their experience in the 12 months time, and thus leaving a possibility of memory bias and overstatements. The final limitation of this study was that the research was a cross-sectional study and thus inadequate for identifying a causal association between independent variables and dependent variables. Despite these limitations, this study is a valuable addition to the scarce research on musculoskeletal disorders of University canteen workers in Nepal.

Further studies involving larger population including other University canteens should be targeted, so that stronger results can be established and can be generalized. Further studies can also focus on level of physical activities, workplace evaluation, stress level and ergonomic status of the kitchen.

\section{CONCLUSION}

The prevalence of work related musculoskeletal disorder among the canteen staffs of Kathmandu University was found to be high. This result suggests the need of timely management to prevent or reduce musculoskeletal disorders amongst the canteen staff. Such conclusion would further necessitate the development of prevention strategy program, short break exercises and ergonomic interventions.

\& World Health Organization. (1985). Identification and control of work-related diseases: report of a WHO expert committee [meeting held in Geneva from 28 November to 2 December 1983][Internet]. Geneva: World Health Organization; 2017 [Cited on July 15, 2017]. [Website]

5. McCauley-Bush P. Ergonomics: Foundational Principles, Applications, and Technologies. CRC Press; 2011. p.359.

6. Nunes LI, McCauley P. Work-Related Musculoskeletal Disorders Assessment and Prevention. In: Nunes IL, editor. Ergonomics - A Systems Approach. In Tech; 2012. [Full Text]

7. Malchaire J, Cock N, Vergracht S. Review of the factors associated with musculoskeletal problems in epidemiological studies. Int Arch Occup Environ Health. 2001 Mar;74(2):79-90. [DOI] 
8. Xu Y-W, Cheng ASK. An onsite ergonomics assessment for risk of work-related musculoskeletal disorders among cooks in a Chinese restaurant. Work. 2014;48(4):539-45.[PubMed]

9. Occupational Safety and Health Council. The Study of Work-related Musculoskeletal Disorders in Catering Industry in Hong Kong [Internet]. Occupational Safety and Health Council; 2011 [Cited on July 17, 2017]. [Full Text]

10. Genç A, Kahraman T, Göz E. The prevalence differences of musculoskeletal problems and related physical workload among hospital staff. J Back Musculoskelet Rehabil. 2016 Aug 10;29(3):541-7. [PubMed]

11. Fjell Y, Osterberg M, Alexanderson K, Karlqvist L, Bildt C. Appraised leadership styles, psychosocial work factors, and musculoskeletal pain among public employees. Int Arch Occup Environ Health. 2007 Oct;81(1):19-30.[PubMed]

12. Cochran DJ. Ergonomics in Desigh: The Quarterly of Human Factors Applications. In: Kuorinka I, Forcier L. Work-Related Musculoskeletal Disorders: A Refernce Book for Prevention. London: Taylor And Francis; 1995.p.421. [DOI]

13. Xu Y-W, Cheng ASK, Li-Tsang CWP. Prevalence and risk factors of work-related musculoskeletal disorders in the catering industry: a systematic review. Work (Reading, Mass). 2013;44(2):107-16. [PubMed]

14. Nagasu M, Sakai K, Ito A, Tomita S, Temmyo Y, Ueno $M$, et al. Prevalence and risk factors for low back pain among professional cooks working in school lunch services. BMC Public Health. 2007 Jul 24;7:171.[Full Text]

15. Pekkarinen A, Anttonen H, Niskanen J. Assessment of Health Risks in Canteen Kitchens. International Journal of Occupational Safety and Ergonomics. 1996 Jan;2(3):262-7. [DOI]

16. Subramaniam S, Murugesan S. Investigation of work-related musculoskeletal disorders among male kitchen workers in South India. International Journal of Occupational Safety and Ergonomics. 2015 Oct 2;21(4):524-31. [DOI]

17. Sripaiboonkij P, Taptakarnporn S. Health Effects on Canteen Staff Working in a University Canteen. Health. 2014 Oct 10;06:2392. [Full Text]

18. Bonauto D, Silverstein B, Adams D, Foley M. Prioritizing industries for occupational injury and illness prevention and research, Washington State Workers' compensation claims, 1999-2003. J Occup Environ Med. 2006 Aug;48(8):840-51. [PubMed]
19. Fjell Y, Alexanderson K, Karlqvist L, Bildt C. Selfreported musculoskeletal pain and working conditions among employees in the Swedish public sector. Work. 2007;28(1):33-46. [PubMed]

20. Hannerz H, Tüchsen F, Kristensen TS. Hospitalizations among employees in the Danish hotel and restaurant industry. Eur J Public Health. 2002 Sep;12(3):192-7. [PubMed]

21. Vaidya A, Sainju NK, Joshi SK. Work related musculoskeletal disorders among surgeons working in a tertiary care hospital in Kathmandu, Nepal. International Journal of Occupational Safety and Health. 2017 Aug 6;5(2):6-10.[DOI]

22. Acharya R, Acharya S, Pradhan A, Oraibi S. Musculoskeletal disorders among dentists in Nepal. Journal of Nepal Dental Association. 2010;11(2):7. [Full Text]

23. Joshi SV, Joshi SK. 112 Injuries and musculoskeletal disorders among young workers in the brick kilns of nepal. Occup Environ Med. 2018 Apr 1;75(Suppl 2):A267-8. [DOI]

24. Kuorinka I, Jonsson B, Kilbom A, Vinterberg $H$, BieringSørensen F, Andersson G, et al. Standardised Nordic questionnaires for the analysis of musculoskeletal symptoms. Applied ergonomics. 1987;18(3):233-7. [PubMed]

25. Shiue H-S, Lu C-W, Chen C-J, Shih T-S, Wu S-C, Yang $\mathrm{C}-\mathrm{Y}$, et al. Musculoskeletal disorder among 52,261 Chinese restaurant cooks cohort: result from the National Health Insurance Data. J Occup Health. 2008;50(2):163-8.[PubMed]

26. Ono $Y$, Nakamura R, Shimaoka M, Hiruta S, Hattori $Y$, Ichihara $G$, et al. Epicondylitis among cooks in nursery schools. Occup Environ Med. 1998 Mar;55(3):172-9. [PubMed]

27. Ncube F, Kanda A, Sanyanga T. Standing working posture and musculoskeletal pain among Citrus sinensis workers in a low-income country. International Journal of Occupational Safety and Ergonomics. 2018 Nov 9;1-8.[DOI]

28. Wong KC, Lee RY, Yeung SS. The association between back pain and trunk posture of workers in a special school for the severe handicaps. BMC Musculoskelet Disord. 2009 Apr 29;10:43. [DOI]

29. Messing K, Kilbom A. Standing and very slow walking: foot pain-pressure threshold, subjective pain experience and work activity. Appl Ergon. 2001 Feb;32(1):81-90.[DOI]

30. Abate M, Vanni D, Pantalone A, Salini V. Cigarette smoking and musculoskeletal disorders. Muscles Ligaments Tendons J. 2013 Jul 9;3(2):63-9.[PubMed] 